Elsevier

GEN 02498

\title{
Transfection of primary human skin fibroblasts by electroporation
}

(Transient expression; CAT assay; stable integration; neomycin resistance; calcium phosphate transformation)

\author{
Jane W. Fountain, Wendy K. Lockwood and Francis S. Collins
}

Howard Hughes Medical Institute and Departments of Human Genetics and Internal Medicine, University of Michigan, Ann Arbor, MI 48109 (U.S.A.)

Received 20 November 1987

Accepted 1 February 1988

Received by publisher 29 April 1988

\section{SUMMARY}

Primary human skin fibroblasts are an accessible source of phenotypically and karyotypically normal human cells, but are difficult to transfect with exogenous DNA. Here we demonstrate that both transient expression and stable transformation can be carried out by the method of electroporation. Highly efficient transient chloramphenicol acetyltransferase expression was shown after transfection with plasmid pRSVCAT. Stable transformation of human skin fibroblasts to G418 resistance was obtained after electroporation with neocontaining plasmids at an efficiency of approximately $1.4 \times 10^{-5} / \mu \mathrm{g}$ DNA. The ability to easily transfect these cells with exogenous DNA may have important applications in the study of human genetic diseases and cancer.

\section{INTRODUCTION}

Starting with the first successful transformation of human cells by Szybalska and Szybalski (1962), several methods of transfection have been devised

Correspondence to: Dr. F.S. Collins, Howard Hughes Medical Institute, Rm 5520A MSRB I, University of Michigan, $1150 \mathrm{~W}$. Medical Center Drive, Ann Arbor, MI 48109-0650 (U.S.A.) Tel. (313)747-3407.

Abbreviations: bp, hase pair(s); CAT, Cm acetyltransferase; $\mathrm{Cm}$, chloramphenicol; FBS, fetal bovine serum; G418, geneticin antibiotic; HSF, human skin fibroblast; kb, kilobase(s) or 1000 bp; MEM, minimal essential medium; neo, neomycin phosphotransferase gene; PBS, phosphate-buffered saline; SV40, simian virus 40 . for the insertion of cloned DNAs into cells. One of the most common methods, calcium phosphate coprecipitation, is quite variable in efficiency from one cell line to another (Gorman et al., 1983). Many of the most transfectable human cell lines are derived from tumor tissues or have been tranformed by SV40 viral or plasmid DNAs (Boggs et al., 1986; Canaani et al., 1986; Murnane et al., 1985; Tainsky et al., 1987; Wood et al., 1987). These cell lines possess properties such as continuous growth, altered cell morphology, and aberrant chromosomal composition that are not found in primary cell cultures produced from normal tissues and are undesirable for some applications. In general, these cell lines are tento 100 -fold more transfectable than primary cell cul- 
tures (Canaani et al., 1986; Murnane et al., 1985; Wood et al., 1987).

A large number of studies are being performed today whose ultimate goals are to draw conclusions about the causes of human cancer. A continuous search goes on for an in vitro cell system that most closely resembles the in vivo situation found in man. Optimally, one would like to study the effects of oncogenes in primary human cells such as HSFs. Furthermore, studies of human genetic diseases, such as familial polyposis of the colon or von Hippel-Lindau syndrome, would be aided by the ability to transfect exogenous DNA into HSFs derived from patients with these rare disorders. Up till now, however, stable transformation of HSFs by DNAs other than SV40 has been demonstrated in a limited number of studies (Chang et al., 1986; Diatloff-Zito et al., 1986; Doniger et al., 1983; Mayne et al., 1986; Shaham et al., 1987, Shimada et al., 1987). Several investigators have been successful in transfecting human foreskin fibroblasts (Fry et al., 1986; Hurlin et al., 1987, Pirisi et al., 1987; Sager et al., 1983; Sutherland and Bennett, 1984). Whether or not transfection efficiencies are comparable between foreskin and epidermal skin fibroblasts is unclear. In addition, HSFs are easily obtainable from patients whereas foreskin or fetal fibroblasts are not available for use in studies involving most genetic diseases.

Electroporation has been used to successfully transfect primary human fetal fibroblasts and a large number of immortalized mammalian cultures (Chu et al., 1987). Knutson and Yee (1987) alluded to successful transfection of HSFs by electroporation but did not provide any confirming data. In this study, we demonstrate successful transient and stable transformation of HSFs using electroporation.

\section{EXPERIMENTAL AND DISCUSSION}

\section{(a) Transient expression using pRSVCAT}

Normal HSFs from skin biopsies of adult volunteers were transfected with pRSVCAT (Gorman et al., 1982a) in order to determine whether these cells were capable of transient expression after

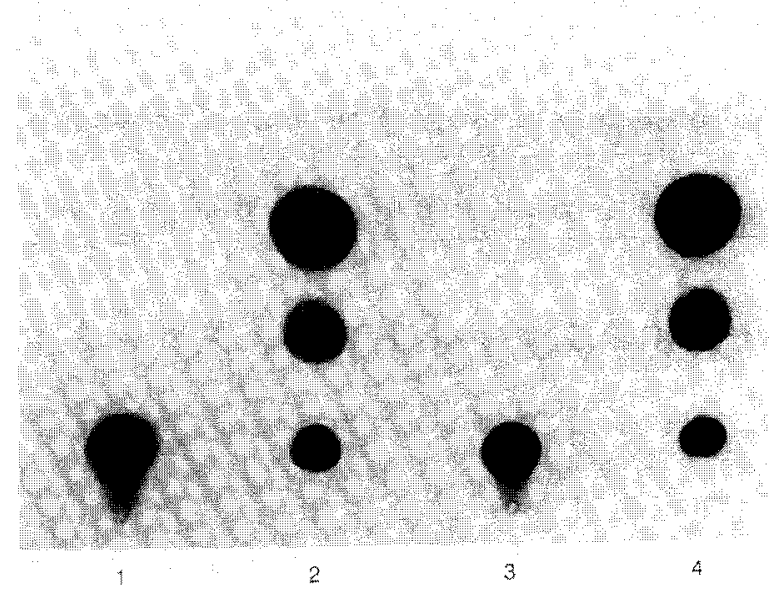

Fig. 1. Transient expression of CAT activity in HSFs. pRSVCAT was transfected into HSFs obtained from two different normal individuals (lanes 2 and 4). Lanes 1 and 3 contain cell extracts from the same individuals that were electroporated without pRSVCAT. Cells were harvested $96 \mathrm{~h}$ after electroporation and $80 \mu 1$ of extract (corresponding to an absorbance of approx. 0.08 at $280 \mathrm{~nm}$ ) was incubated with $\left[{ }^{14} \mathrm{C}\right]$ chloramphenicol and acetyl coenzyme A overnight. CAT activity was measured by thin-layer chromatography as described by Gorman et al. (1982b).

electroporation. This plasmid ( $50 \mu \mathrm{g}$ of pRSVCAT) was transfected into $10^{6}$ to $10^{7}$ early passage cells. Trypsinized cells and DNA were suspended in $500 \mu 1$ of PBS and pipetted into alcohol-sterilized plastic cuvettes (Sarstedt). As previously described by Potter et al. (1984), a $2000 \mathrm{~V}$ electrical pulse was applied to the suspension with stainless steel electrodes using an ISCO model 494 electrophoresis power supply. Electroporated cells were replated into flasks and fed with Eagle's MEM (Gibco) supplemented with $15 \%$ FBS (Gibco). After $96 \mathrm{~h}$ of incubation, transfected HSFs were harvested and CAT assays were performed on cell extracts according to Gorman et al. (1982b). Results showed that HSFs were capable of taking up and expressing foreign DNA using the method of electroporation (Fig. 1). The level of expression compared favorably with that seen in calcium phosphate-transfected HeLa cells (not shown).

\section{(b) Stable integration using pHneo}

We also wished to determine whether DNA that entered HSFs was capable of becoming integrated into the cellular genome. In order to fulfill this goal, 
we initially transfected HSFs with pHneo, pHneo is a vector in which deleterious out-of-frame initiation codons within the 5 -untranslated region of the neo gene have been eliminated (personal communication, C.C. Simonsen, In Vitro, San Carlos, CA). The pHneo construct provided us with a selectable marker for obtaining stably transfected clones.

Briefly, $2 \mu \mathrm{g}$ of $P v u \mathrm{I}$-linearized pHneo was suspended with $10^{6}$ to $10^{7}$ cells in $500 \mu 1$ of PBS and electroporation was performed as described for the pRSVCAT transfection. Transfected cells were replated into petri dishes and fed with $15 \%$ FBS MEM. After $48 \mathrm{~h}, \mathrm{G} 418$ selective medium, containing $400 \mu \mathrm{g} / \mathrm{ml}$ of active geneticin (Gibco) in $15 \%$ FBS MEM, was added to the cultures. Cells were maintained in G418 medium for approx. four weeks at which time they were assumed to be fully selected and were placed back into $15 \%$ FBS MEM without geneticin. Untransfected HSFs and cells electroporated without DNA survived a maximum of one week in G418 medium. Stably transfected clones were counted three weeks after transfection and DNA was isolated from these clones after about eight weeks.

Fig. 2 shows that by Southern blotting a representative number of transfected HSF clones contained sequences homologous to the pHneo plasmid. As judged by copy controls, the pHneo sequences appeared to integrate as concatemers of three to ten copies at a single site in the cellular genome.

\section{(c) Comparison to calcium phosphate method of transfection}

Next, we wanted to compare electroporation with the calcium phosphate method of transfection. In conjunction with this study, we were also interested in determining whether transfection efficiencies differed between two related vectors, namely $\mathrm{pHneo}$ and pSV2neo (Southern and Berg, 1982). Electroporation assays were carried out using molar equivalents of $P v u \mathrm{I}$ linearized pHneo $(2 \mu \mathrm{g})$ and $P v u \mathrm{I}$ linearized pSV2neo $(2.2 \mu \mathrm{g})$. Calcium phosphate-DNA co-precipitations were performed using a standard protocol (Graham and Van der Eb, 1973). In these assays, $75 \mu \mathrm{g}$ of sheared human placental DNA was used as carricr along with the same quantities of neo DNAs that were utilized for the electroporations. A 1-min glycerol shock was
TABLE I

Transfection efficiencies for $\mathrm{pHneo}$ and $\mathrm{pSV} 2$ neo in human skin fibroblasts

\begin{tabular}{lll} 
Plasmid $^{\mathrm{a}}$ & Transfection efficiencies $^{\mathrm{b}}$ \\
\cline { 2 - 3 } & Electroporation $^{\mathrm{c}}$ & Calcium phosphate $^{\mathrm{d}}$ \\
\hline pHneo & $0.8 \times 10^{-5}$ & $1.0 \times 10^{-6}$ \\
pSV2neo & $1.4 \times 10^{-5}$ & $0.5 \times 10^{-6}$ \\
\hline
\end{tabular}

${ }^{a} P v u \mathrm{I}$ linearized plasmids were transfected into HSFs as described in sections $\mathbf{b}$ and $\mathbf{c}$.

b Expressed as colonies/number of transfected cells/ $\mu$ g neo plasmid.

c Electroporations were performed as described in section a.

4 Calcium phosphate transfections were performed as described in section $\mathbf{c}$.

performed on the calcium phosphate transfected cells $5 \mathrm{~h}$ after transfection (Gorman et al., 1983). Clones were counted three weeks after the transfections. Results are summarized in Table I.

\section{(d) Conclusions and additional observations}

In our hands, electroporation proved to be eightto 28-fold more efficient than calcium phosphate transfection of primary HSFs. Jastreboff et al. (1987) noted a similar increase in transfection efficiency when comparing electroporation to calcium phosphate transfection in NIH3T3 cells. In addition, we noted that after two weeks in G418 medium, electroporated clones were, in general, much larger than calcium phosphate-transfected clones. At the end of three weeks in selective medium, calcium phosphate-transfected clones remained difficult to visualize without the aid of a microscope. Possible reasons for this observation would include residual toxicity from the glycerol shock, growth stimulation from the electrical pulse, or more effective expression of the G418 resistance gene after electroporation.

Our results showed that $\mathrm{pSV} 2$ neo had a slightly higher frequency of transformation to $\mathrm{G} 418$ resistence than pHneo. Our electroporation studies with pSV2neo yielded a transformation efficiency of $1.4 \times 10^{-5} / \mu \mathrm{g}$ DNA in HSFs. The efficiency for pHneo was $0.8 \times 10^{-5} / \mu \mathrm{g}$ DNA. 


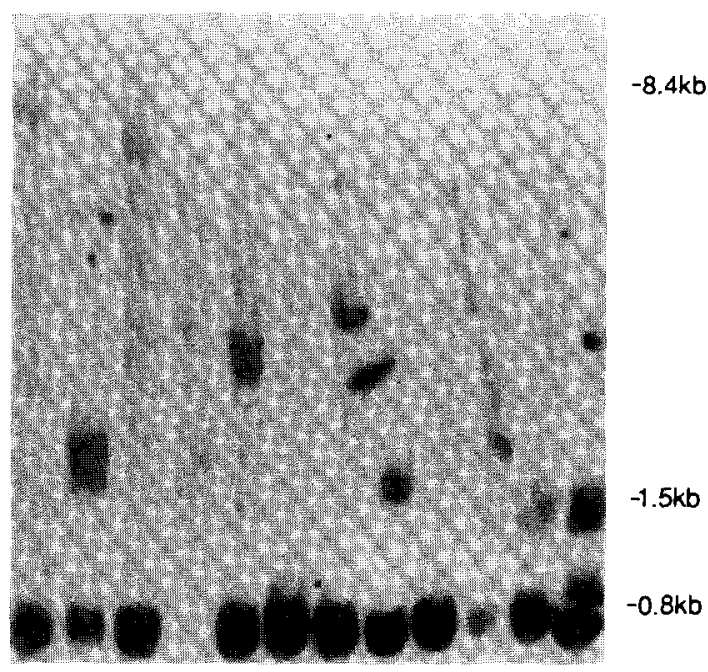

B

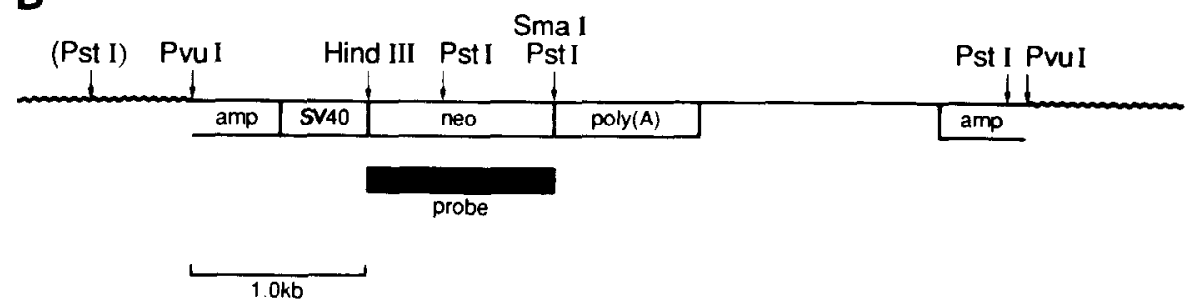

Fig. 2. Stable transfection of pHneo in HSFs. (Panel A) Analysis of pHneo-transfected clonal DNAs. DNAs isolated from stably transformed G418-resistant colonies were restricted with Pst I, electrophoresed on a 1\% agarose gel, and transferred to GeneScreen Plus using 0.4 M NaOH. Hybridization was performed using a HindIII-SmaI fragment of pHneo as a probe and following hybridization conditions recommended by the manufacturer (NEN) (Davis et al., 1986; Feinberg and Vogelstein, 1983). HSFs were transfected with $P v u$ I linearized pHneo, selected in G418 medium [15\% FBS MEM containing $400 \mu \mathrm{g} / \mathrm{ml}$ of active geneticin (Gibco)], and picked as clones prior to DNA extraction. Lanes 1-3 and 5-9 represent individual clones that arose from HSFs transfected with pHneo. In lane 4, DNA from untransfected HSFs was used as a negative control. Lanes 10-12 are copy controls which were created by adding 1,3 , or 10 molar equivalents of circular pHneo to placental DNA before digesting with $P_{s t} \mathrm{I}$. All DNAs were restricted with $P_{s t} \mathrm{I}$ in order to visualize the number of insertion sites in each clone. The presence of one additional fragment in each clone is indicative of a single site of integration. (Map B) Schematic representation of an integrated copy of pHneo along with the HindIII-SmaI probe used in this experiment. The straight lines and boxed-in regions indicate the order of pHneo sequences when this vector is linearized with $P v u I$ and the wavy lines represent genomic DNA surrounding the integration site. This probe hybridizes with a constant 0.8 -kb $P_{s t} \mathrm{I}$ fragment in each DNA digestion as seen in panel A (lanes 1-3 and 5-12). An additional PstI fragment of variable size is also visualized in clonal DNAs (panel A, lanes 1-3 and 5-9) depending on where the nearest Pst I site lies in genomic DNA upstream of the integration site. This variable Pst I site is indicated in parentheses. When circular $\mathrm{pHneo}$ is digested with Pst $\mathrm{I}$, an additional constant fragment of $1.5 \mathrm{~kb}$ is also present. This fragment is seen in the copy controls (panel A, lanes 10-12).

We have also successfully co-transfected pHneo along with a non-selectable marker which expresses the viral myc oncogene, pSV-v-myc (Land et al., 1983), into HSFs (not shown). Co-transfections were performed using a ten-fold excess of $\mathrm{pSV}-\mathrm{v}-m y c$ along with $2 \mu \mathrm{g}$ of pHneo. Efficiencies were approx. ten-fold lowcr for co-transfections than for neo transfections alone, indicating to us that higher quantities of DNA may be toxic to the cells. It is also possible that myc expression from the $\mathrm{pSV}-\mathrm{v}-m y c$ vector may be deleterious to HSF growth. Stevenson and Volsky (1986) reported some instability of the pSV-v-myc plasmid when transfecting human lymphocytes using a Sendai virus envelope-mediated gene transfer technique. In addition, Newbold and Ovcrcll (1983) noted a substantial decreasc in the formation of calcium phosphate-transfected rolonies when they co-transfected a dihydrofolate reductase 
plasmid along with a EJras-containing plasmid into primary hamster dermal fibroblasts. Thus, certain oncogene-expressing plasmids may be deleterious to primary cells, regardless of the transfection method employed.

An alternative approach which bypasses these co-transfection difficulties is the use of vectors that contain both neo and oncogene sequences. We have successfully transfected into HSFs a vector that contains a 6.6-kb Bam HI EJras insert ligated into a SalI site of pHneo, at efficiencies of approx. $0.6 \times 10^{-5} / \mu \mathrm{g}$. In addition, we have been able to successfully transfect HSFs using a number of other neo- and oncogene-containing constructs obtained from M.A. Tainsky (Tainsky et al., 1987).

In this brief communication, we have demonstrated that primary HSFs can be efficiently transfected by electroporation. We feel electroporation offers several advantages over other current methods of transfection. First, a relatively small amount of DNA is required to transform a large number of cells ( $2 \mu \mathrm{g} / 10^{6}$ to $10^{7}$ cells). Second, no carrier DNA is required. Third, no toxic substances such as dimethylsulfoxide, glycerol, polyethylene glycol, or sodium butyrate ever come into contact with the cells. And, finally, no labor-intensive procedures are involved as in protoplast fusion, nuclear injection, lipofection (Felger et al., 1987), and Sendai virus envelope-mediated gene transfer techniques. Electroporation thus allows for convenient transfection of cloned DNAs into HSFs, and will now permit more detailed studies of the expression of cloned DNAs in normal (untransformed) human cells.

\section{ACKNOWLEDGEMENTS}

This work was supported in part by NIH grant NS23427 to F.S.C. and NIH training grant NIH-5T32-GM07544-10 to J.W.F. F.S.C. is an assistant investigator of the Howard Hughes Medical Institute.

\section{REFERENCES}

Boggs, S.S., Gregg, R.G., Borenstein, N. and Smithies, O.: Efficient transformation and frequent single-site, single-copy insertion of DNA can be obtained in mouse erythroleukemia cells transformed by electroporation. Exp. Hematol. 14 (1986) 988-994.

Canaani, D., Naiman, T., Teitz, T. and Berg, P.: Immortalization of Xeroderma pigmentosum cells by simian virus 40 DNA having a defective origin of DNA replication. Somat. Cell Mol. Genet. 12 (1986) 13-20.

Chang, P.L., Gunby, J.L., Tomkins, D.J., Mak, I., Rosa, N.E. and Mak, S.: Transformation of human cultured fibroblasts with plasmids carrying dominant selection markers and immortalizing potential. Exp. Cell Res. 167 (1986) 407-416.

Chu, G., Hayakawa, H. and Berg, P.: Electroporation for the efficient transfection of mammalian cells with DNA. Nucleic Acids Res. 15 (1987) 1311-1326.

Davis, L.G., Dibner, M.D. and Battey, J.F.: Basic Methods in Molecular Biology. Elsevier, New York, 1986.

Diatloff-Zito, C., Papadopoulo, D., Averbeck, D. and Moustacchi, E: Abnormal response to DNA crosslinking agents of Fanconi anemia fibroblasts can be corrected by transfection with normal human DNA. Proc. Natl. Acad. Sci. USA 83 (1986) 7034-7038.

Doniger, J., Di Paolo, J.A. and Popescu, N.C.: Transformation of Bloom's Syndrome fibroblasts by DNA transfection. Science 222 (1983) 114-146.

Feinberg, A.P. and Vogelstein, B.: A technique for radiolabeling DNA restriction endonuclease fragments to high specific activity. Anal. Biochem. 132 (1983) 6-13.

Felger, P.L., Gadek, T.R., Holm, M., Roman, R., Chan, H.W., Wenz, M., Northrop, J.P., Ringold, G.M. and Danielsen, M.: Lipofection: a highly efficient, lipid-mediated DNA-transfection procedurc. Proc. Natl. Acad. Sci. USA 84 (1987) $7413-7417$.

Fry, D.G., Milam, L.D., Maher, V.M. and McCormick, J.J.: Transformation of diploid human fibroblasts by DNA transfection with the v-sis oncogene. J. Cell. Physiol. 128 (1986) 313-321.

Gorman, C.M., Merlino, G.T., Willingham, M.C., Pastan, I. and Howard, B.H.: The Rous sarcoma virus long terminal repeat is a strong promoter when introduced into a variety of eukaryotic cells by DNA-mediated transfection. Proc. Natl. Acad. Sci. USA 79 (1982a) 6777-6781.

Gorman, C.M., Moffat, L.F. and Howard, B.H.: Recombinant genomes which express chloramphenicol acetyltransferase in mammalian cells. Mol. Cell. Biol. 2 (1982b) 1044-1051.

Gorman, C.M., Padmanabhan, R. and Howard, B.: High efficiency DNA-mediated transformation of primate cells. Science 221 (1983) 551-553.

Graham, F.L. and Van der Eb, A.J.: A new technique for the assay of infectivity of human adenovirus 5 DNA. Virology 52 (1973) 456-467.

Hurlin, P.J., Fry, D.G., Maher, V.M. and McCormick, J.J.: Morphological transformation, focus formation, and anchorage independence induced in diploid human fibroblasts by expression of a transfected H-ras oncogene. Cancer Res. 47 (1987) 5752-5757.

Jastreboff, M.M., Ito, E., Bertino, J.R. and Narayanan, R.: Use of electroporation for high-molecular-weight DNA-mediated gene transfer. Exp. Cell Res. 171 (1987) 513-517.

Knutson, J.C. and Yee, D.: Electroporation: paramctcrs affecting 
transfer of DNA into mammalian cells. Anal. Biochem. 164 (1987) 44-52.

Land, H., Parada, L.F. and Weinberg, R.A.: Tumorigenic conversion of primary embryo fibroblasts requires at least two cooperating oncogenes. Nature 304 (1983) 596-602.

Mayne, L.V., Priestley, A., James, M.R. and Burke, J.F.: Efficient immortalization and morphological transformation of human fibroblasts by transfection with SV40 DNA linked to a dominant marker. Exp. Cell Res. 162 (1986) 530-538.

Murnane, J.P., Fuller, L.F. and Painter, R.B.: Establishment and characterization of a permanent $\mathrm{pSV}$ ori ${ }^{-}$-transformed Ataxia-Telangiectasia cell line. Exp. Cell Res. 158 (1985) $119-126$.

Newbold, R.F. and Overell, R.W.: Fibroblast immortality is prerequisite for transformation by EJ c-Ha-ras oncogene. Nature 304 (1983) 648-651.

Pirisi, L., Yasumoto, S., Feller, M., Doniger, J. and DiPaolo, J.A.: Transformation of human fibroblasts and keratinocytes with human papillomavirus type 16 DNA. J. Virol. 61 (1987) 1061-1066.

Potter, H., Weir, L. and Leder, P.: Enhancer-dependent expression of human $\kappa$ immunoglobuin genes introduced into mouse pre-B lymphocytes by electroporation. Proc. Natl. Acad. Sci. USA 81 (1984) 7161-7165.

Sager, R., Kiyoji, T., Lau, C.C., Ebina, Y. and Anisowicz, A.: Resistance of human cells to tumorigenesis induced by cloned transforming genes. Proc. Natl. Acad. Sci. USA 80 (1983) 7601-7605.

Shaham, M., Adler, B., Ganguly, S. and Chaganti, R.S.K.: Transfection of normal human and Chinese hamster DNA corrects diepoxybutane-induced chromosomal hypersensitivity of Fanconi anemia fibroblasts. Proc. Natl. Acad. Sci. USA 84 (1987) 5853-5857.

Shimada, T., Dowjat, W.K., Ginhart, T.D., Lerman, M.I. and Colburn, N.H.: Lifespan extension of Basal Cell Nevus Syndrome fibroblasts by transfection with mouse pro or v-myc gencs. Int. J. Cancer 39 (1987) 649-655.

Southern, P.J. and Berg, P.: Transformation of mammalian cells to antibiotic resistance with a bacterial gene under control of the SV40 early region promoter. J. Mol. Appl. Genet. 1 (1982) 327-341.

Stevenson, M. and Volsky, D.J.: Activated v-myc and v-ras oncogenes do not transform normal human lymphocytes. Mol. Cell. Biol. 6 (1986) 3410-3417.

Sutherland, B.M. and Bennett, P.V.: Transformation of human cells by DNA transfection. Cancer Res. 44 (1984) 2769-2772.

Szybalska, E.H. and Szybalski, W.: Genetics of human cell lines, IV. DNA-mediated heritable transformation of a biochemical trait. Proc. Natl. Acad. Sci. USA 48 (1962) 2026-2034.

Iainsky, M.A., Shamanski, F.L., Blair, D. and Van de Woude, G.: Human recipient cell for oncogene transfection studies. Mol. Cell. Biol. 7 (1987) 1280-1284.

Wood, C.M., Timme, T.L., Hurt, M.M., Brinkley, B.R., Ledbetter, D.H. and Moses, R.E.: Transformation of DNA repair-deficient human diploid fibroblasts with a Simian virus 40 plasmid. Exp. Cell Res. 169 (1987) 543-553.

Communicated by J.L. Slightom. 